\title{
Simulation and Optimization of Polymerization Reactor for the Production of Polyethylene Terephthalate (PET)
}

\author{
Ahmad F'*, Mr. Hamza Nisar ${ }^{2}$, Naveed Ahmad ${ }^{3}$ \\ ${ }^{1}$ Department of Chemical Engineering, University of \\ WAH, Pakistan \\ ${ }^{2}$ University of Wah Wah Engineering College Chemical \\ Department, Pakistan \\ ${ }^{3}$ Arid University, Department of Microbiology, Pakistan \\ *Corresponding author: Fazeel Ahmad, Department \\ of Chemical Engineering, University of WAH, WAH \\ Engineering College, Pakistan
}

Received: J anuary 18, 2021; Accepted: February 12, 2021; Published: February 19, 2021

\begin{abstract}
The sole objective of this paper is to investigate Simulation and Optimization process for the production of polyethylene terephthalate, the biggest polymer being consumed all over the world. In this way, two polymerization reactors are replaced with one polymerization reactor. In this way equipment and operating and many other cost was reduced. Discussion has also been made on the optimum temperature and pressure along with most suitable catalyst. The objective function for the polymerization reactor is to maximize the production as well as conversion. It is found that the reactor should be operated at a high temperature initially to obtain high conversion of Dimethyl Terephthalate (DMT) first, but then it should be lowered to reduce the formation of side products. Previous work was done on Simulation for the batch reactor only but in this work the Simulation was applied to the continuous polymerization reactor and results is investigated.
\end{abstract}

Keywords: Mono ethylene glycol; Pure terephthalic acid; Esterification; Polycondensation; Polyethylene terephthalate; Simulation; Optimization

\section{Introduction}

Polyethylene Terephthalate (PET) is the raw material for the production of synthetic fibers, films, filaments and plastic objects. PET is one of the most important polymers from a commercial point of view. Fiber-grade PET is mainly used in textiles, and its contribution to the world synthetic fiber demand is around $40 \%$.

Polyethylene Terephthalate (PET) is widely consumed in industrial and residential areas because of its excellent properties (e.g., high thermal stability, clarity, low cost, excellent tensile, and impact strength; but its expansion and disposal have led to serious environmental issues. Incineration and landfill are common methods of waste disposal. However, incineration results in the release of toxic substances that are harmful to health. Commercial PET and PET with high degrees of crystallinity have a melting point of $255-265^{\circ} \mathrm{C}$ and 260-265 ${ }^{\circ} \mathrm{C}$, respectively.

The production of PET proceeds via two stages: (1) a transesterification stage or esterification stage; (2) a polycondensation stage. In the First stage, prepolymer (monomer for the polycondensation stage) containing mainly Bis (2-Hydroxyethyl) Terephthalate (BHET) is synthesized either through the transesterification of Dimethyl Terephthalate (DMT) and Ethylene Glycol (EG) or through the direct esterification of Terephthalic Acid (TPA). About 50 million tons of this material is produced annually, from a very high amount of TPA and MEG, both derived from petroleum [1]. It is found that the reactor should be operated at a high temperature initially to obtain high conversion of Dimethyl Terephthalate (DMT) first, but then it should be lowered to reduce the formation of side products $[2,3]$.

PET is non-degradable under normal conditions. In 2017, the total global plastic production reached 348 million tonnes, $29.4 \%$ of which came from China. However, half of the plastics produced are for single use. In 2015, approximately $7 \%$ of the plastic demand was constituted by PET worldwide; reaching 18.8 million tons. Polyethylene terephthalate is the raw material for the production of synthetic fiber, films, filaments and plastic bottles. PET is one of the most important polymers from a commercial point of view [4].

Fibre-grade PET is mainly used in textiles, and its contribution to the world synthetic bre demand is around $40 \%$. Polyester is a category of polymers, which contain the ester functional group in their main chain. Although there are many types of polyester, the term "polyester" as a specific material most commonly refers to Polyethylene Terephthalate (PET). A chemical reaction bonding monomer together to make a polymer is called polymerization. Polymers are substances whose molecules have high molar masses and are composed of a large number of repeating units. Pure Terephthalic Acid (PTA) and Mono Ethylene Glycol (MEG), Catalyst are mixed to produce oligomer and water in the Etherification section. The oligomer is converted to polymer through polymerization reaction and is sent to spinning and the spin product is sent for drawing after which it is baled and cut. After cutting, the product is sent to warehouse.

In this paper process description, optimization, uses, supply and demand of polyester has been discussed. Optimized the process, by reducing the number of reactors to achieve the desired product rate is the biggest achievements. Polycondensation is the actual "chain building" step in the making of polyester polymer. The optimum requirements for the best production include optimum operating temperature and optimum operating pressure along with highest achieved conversion. The reaction in order to proceed forward requires the addition of a catalyst, typically antimony, as well as heat and vacuum. The chemical linkage between two molecules forming one large molecule. Material balance importance first step when designing a new process or analyzing. They are almost always pre 
requisite to all other calculation in the solution of process engineering a material balance is an accounting for material. Thus, material balance is often compared to the balancing of current account. They are used in industry to calculate mass flow rates of different stream entering or leaving chemical or physical process, beverages, especially convenience-sized soft drinks, juices and water. Polyethylene terephthalate is a condensation polymer of ethylene glycol and terephthalic acid. Polyethylene terephthalate is frequently shortened to PET or PETE. In order to produce PET, there are two major processes, called direct esterification and trans esterification, where direct esterification used Ethylene Glycol (EG) and Terephthalic Acid (TPA) as its raw material while transesterification used EG and Dimethyl Terephthalate (DMT).

Polyester is a category of polymers which contain the ester functional group in their main chain. Although there are many types of polyester, the term "polyester" as a specific material most commonly refers to Polyethylene Terephthalate (PET). Natural polyesters and a few synthetic ones are biodegradable, but most synthetic polyesters are not. Depending on the chemical structure, polyester can be a thermoplastic or thermoset; however, the most common polyesters are thermoplastics. Fabrics woven or knitted from polyester thread or yarn are used extensively in apparel and home furnishings, from shirts and pants to jackets and hats, bed sheets, blankets, upholstered furniture and computer mouse mats.

Polyethylene Terephthalate (PET) is a thermoplastic polymer which comes off to the polyester family with a chemical formula of $\left(\mathrm{C}_{10} \mathrm{H}_{8} \mathrm{O}_{4}\right)$ n. It is a rigid and dimensionally stable substance that absorbs very little water. It is a pure, strong, and lightweight plastic that is vastly used for packing foods.

\section{Materials and Methods}

Succeeding are the important raw material which necessary for production of Polyethylene terephthalate;

\section{Purified Terephthalic Acid (PTA)}

Synonym: 1,4 benzenedicarboxylic acid Chemical

Formula: $\mathrm{C}_{6} \mathrm{H}_{4}(\mathrm{COOH})_{2}$ Molecular

Weight: $166.13 \mathrm{~g} / \mathrm{mol}$

\section{Mono Ethylene Glycol (MEG)}

Synonym: 1,2 ethanediol Chemical

Formula: $\mathrm{C}_{2} \mathrm{H}_{6} \mathrm{O}_{2}$ Molecular

Weight: $62.07 \mathrm{~g} / \mathrm{mol}$

\section{Antimony Trioxide (ATO)}

Chemical Formula: $\mathrm{Sb}_{2} \mathrm{O}_{3}$ Molecular

Weight: $291.51 \mathrm{~g} / \mathrm{mol}$

\section{Process Description for Trans Esterification Method}

Ethylene glycol is drawn from raw material storage and fed to a mix tank, where catalysts and additives are mixed in. From the mix tank, the mixture is fed, along with DMT, to the esterifiers, also known as ester exchange reactors. The methanol vapor must be removed from the esterifiers to shift the conversion to produce more BHET. The vent from the esterifiers is fed to the methanol recovery system, which separates the methanol by distillation in a methanol column. The BHET monomer, with other esterifier products, is fed to a prepolymerization reactor where the temperature is increased to 230 to $285^{\circ} \mathrm{C}$, and the pressure is reduced to between 1 and 760 millimeters of mercury. Product from the prepolymerizer is fed to one or more polymerization reactors, in series. The temperature is further increased to 260 to $300^{\circ} \mathrm{C}$. The final temperature and pressure depend on whether low or high viscosity PET is being produced. For high-viscosity PET, the pressure in the final finisher is less than $2 \mathrm{~mm}$ $\mathrm{Hg}$. With high-viscosity PET, more process vessels are used than low viscosity PET to achieve the higher temperatures and lower pressures needed [5-7].

The ethylene glycol recovery system usually is a distillation system composed of a low boiler column, a refining column, and associated equipment. In such a system, the ethylene glycol condensate is fed to the low boiler column. The top product from this column is sent to a condenser, where methanol condensed and sent to methanol storage. The bottom product of the low boiler column goes to it reboiler, with the vapor recycled back to the low boiler column and the underflow sent to the refining column $[8,9]$.

\section{Process Description for Direct Esterification Method}

The most important steps involved in the process of polyethylene terephthalate by PTA and MEG are: TPA powder is purchased in $1000 \mathrm{~kg}$ bags and unloaded into a storage silo by means of a pressurized inert gas transfer system. The powder is then metered with a screw conveyor into a slurry mix tank where it is mixed with heated glycol in ratio of 2:1. The glycol that is mixed with the TPA in slurry mix tank is a combination of virgin and recaptured glycol. The glycol is accumulated and fed from an agitated tank through filters and into pump. Ratio of glycol to TPA is controlled by a signal from a densitometer which refixeds the magnetic flow meter. The flow rate also measures and records the glycol flow. The temperature of the glycol being fed to the slurry mix tank is approximately $308 \mathrm{~K}$. The mixing of TPA and glycol (slurry) is a continuous process and is controlled automatically by ratio control of the raw material fed streams. From the slurry mix tank, the slurry is fed to the slurry hold tank which supplies the metering pumps feeding slurry into the esterifier through injection nozzles $[3,4]$.

\section{Esterification section}

The reaction of the TPA and the glycol combination is accomplished in the esterifier, which is a combination of a cross arm heat exchanger and a vapour separator [6,7]. The slurry is inserted into the lowest of the heat exchanger and natural flow of the slurry mixture up complete the heat exchanger heats the slurry from approximately $525 \mathrm{~K}$ to $540 \mathrm{k}$, causing the reaction to take place. $\mathrm{H} 2 \mathrm{O}$ formed in the reaction, excess glycol and small quantities of oligomer is taken off the upper of the vapour separator through a heated vapour line into a $\mathrm{H} 2 \mathrm{O}$ separation column wherever the $\mathrm{H} 2 \mathrm{O}$ and glycol vapors are condensed and separated. The excess glycol is pumped to the recollected glycol hold tank for use in making slurry [10].

$$
\mathrm{C}_{2} \mathrm{H}_{6} \mathrm{O}_{2}+\mathrm{C}_{8} \mathrm{H}_{6} \mathrm{O}_{4} \longleftrightarrow \mathrm{C}_{12} \mathrm{H}_{14} \mathrm{O}_{6}+2 \mathrm{H}_{2} \mathrm{O}
$$




\section{Polymerization reactor}

In the polymerization vessel, further reacts the oligomer to form polyester polymer of the desired viscosity, luster and color suitable for spinning. The process involves removing excess glycol to link up polymer chains. This is accomplished by subjecting the polymer to progressively lower pressure and higher temperatures in the Disk Ring Reactor.

$$
2 \mathrm{C}_{12} \mathrm{H}_{14} \mathrm{O}_{6} \longleftrightarrow\left(\mathrm{C}_{10} \mathrm{H}_{8} \mathrm{O}_{4}\right) \mathrm{n}+\left(\mathrm{n}^{-1}\right) \mathrm{C}_{2} \mathrm{H}_{6} \mathrm{O}_{2}
$$

\section{Disk ring reactor}

The main function of the final polycondensation stage is to complete the reaction to the final polymer target. The reactor consists of a horizontal cylindrical vessel provided with built in chamber and a horizontal agitator having many disc rings. The disc rings are arranged in each of these chambers. These rings are used to lift up the product from the chambers and form a thin film which enables the excess glycol is withdrawn immediately under vacuum and polycondensation [9].

\section{Simulation on PET Production Process}

Figure 1 shows the simulation process for the Polyethylene Terephtahlate production process including complete process units. The basic purpose of Simulation is to optimize the process with optimum achievable temperature at which the conversion is maximum. The other most suitable requirement is the use of catalyst which may increase your process efficiency. For the present work the most suitable catalyst is antimony trioxide. The industrialist spends lot of money on equipment cost as well as maintenance cost. The main focus has been remained on the maximum profit at the minimum cost (purchase and operating) $[1,11]$.

\section{Results and Discussion}

\section{Optimized polyethylene terephtahlete production process}

Figure 2 depicts the optimized process for the production of polyethylene terephthalate in which two-polymerization reactor are being replaced with one reactor. In Esterification Section, we use one CSTR reactor instead of two CSTR in series. To get our desired results, we fixed the pressure of the reactor to 0.16 bar and the temperature is calculated by using the Aspen Hysys that is $272^{\circ} \mathrm{C}$ At that temperature, we get the conversion of $90 \%$ of reactant into desired product that is Bis-Hydroxy-Ethylene-Terephthalate (BHET). In polymerization Section, if we change the operating conditions to 0.055 bar and $585 \mathrm{k}$ then we use one CSTR reactor to get our desired

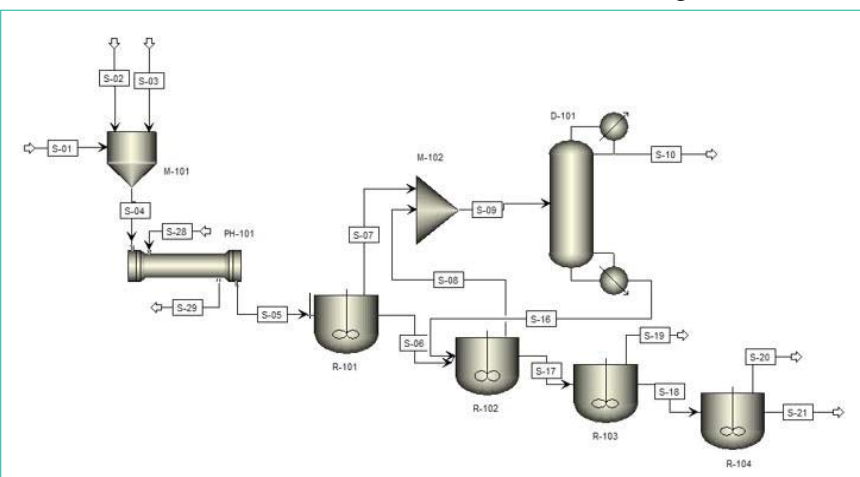

Figure 1: PET Production process flow diagram



Figure 2: Optimized Process Flow Diagram for PET Plant.

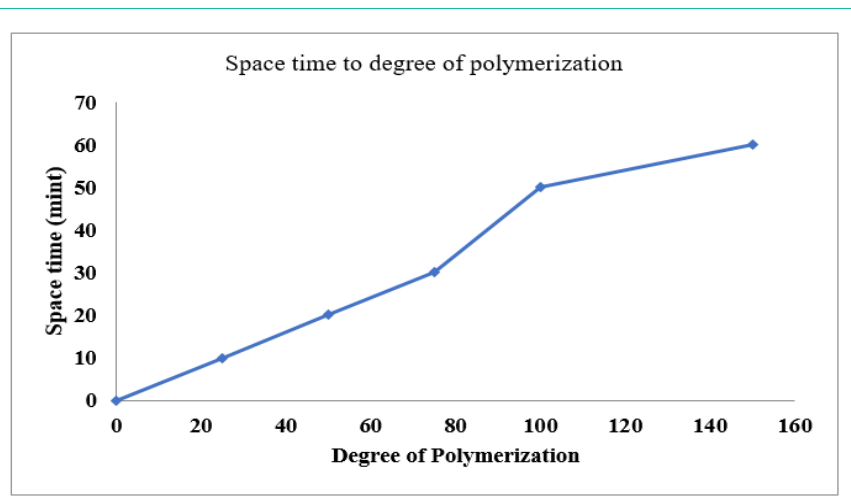

Figure 3: Effect of space time on the degree of polymerization.

results. These conditions of temperature and pressure are calculated by using the Aspen Hysys Simulation. At these conditions, we are able to generate the polymerization length (120) that is actually require.

\section{Effect of space time on the degree of polymerization}

Figure 3 shows the effect of space time on the degree of polymerization. Degree of polymerization increases from 20 to 100 as the space time/holding time is increased from 10 mints to 50 mints. But after that there is increasing as well as decreasing trend in the degree of polymerization with increasing space time. The optimum value of degree of polymerization achieved was 104 .

\section{Effect of space-time on conversion}

Figure 4 shows the effect of space time on conversion. Space time



Figure 4: Effect of space time on the conversion. 


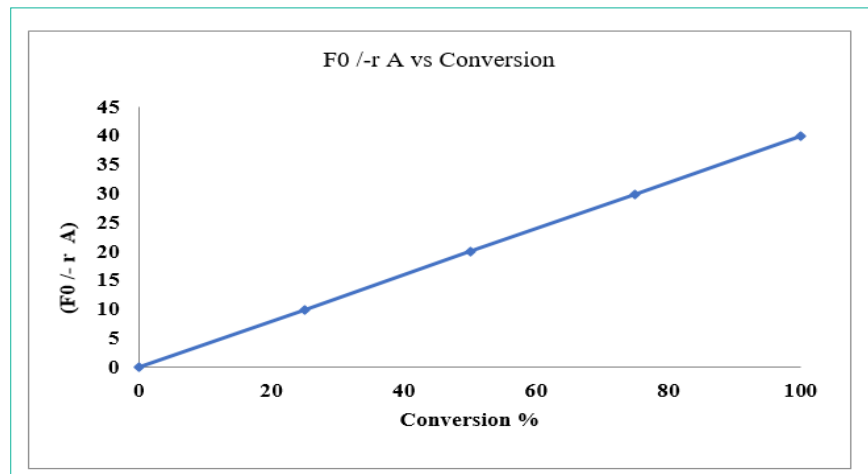

Figure 5: Effect of molar flow rate on the conversion.

is the time for continuous reactor in which reactants spend the time in the reactors to be converted into products. The space time directly related to the conversion. The higher space time corresponds to the higher conversions. The conversion in the space time interval (0-10) minutes increases up to 25 . Similarly, as the space time increases from (10-32) minutes the conversion achieve higher maximum value about $100 \%$.

\section{Effect of molar flow rate on conversion}

Figure 5 represents the relation between molar flow rate and conversion. Below trend show that molar flow rates and conversion both are directly related with each other. As the rate is increased from $5-40$, the conversion increase its lowest value to highest value (0$100 \%)$. The maximum rate value which is obtained is 40 and at that value the conversion achieved is $100 \%$.

\section{References}

1. Encyclopedia of Textiles. $3^{\text {rd }}$ edition. Prentice-Hall, Inc. 1980; 28-33.
2. Kumar A, Sukthankar VK, Gupta SK, Optimization of the transesterification stage of polyethylene terephthalate reactors. Polym Eng Sci. 1984; 24: 185193.

3. Ravindranath K, Mashelkar RA. Polyethylene Terephthalate-I. Chemistry, Thermodynamics and Transport Properties. Chem Eng Sci. 1986; 41: $2197-$ 2214.

4. Napper IE, Thompson RC. "Release of Synthetic Microplastic Plastic Fibres From Domestic Washing Machines: Effects of Fabric Type and Washing Conditions". Marine Pollution Bulletin. 2016.

5. Polyester: Fifty Years of Achievement. State Mutual Book \& Periodical Service. 1993

6. Fellingham C. "Will You Learn to Love Polyester?" Glamour. 1992; 204.

7. Modern Plastics Encyclopedia. 1988, Mcgraw Hill, New York. 1988.

8. Written communication from RK. Smith, Allied Chemical, Moncure, NC, to DR. Goodwin, US. Environmental Protection Agency. Research Triangle Park, NC. 1980.

9. Kumar A, Gupta S K. Fundamentals of polymer science and engineering (New Tata McGraw Hill. 1978.

10. RiteshIngale, Thakur R, Sharma V, Suryawanshi MA, BMane V. Design and Study of Manufacturing of Polyester Plant Using PTA and MEG. 2017.

11. Williams A. "Washing clothes releases thousands of microplastic particles into environment, study shows". Plymouth University. 2016.

12. Corbman BP. Textiles: Fiber to Fabric. $6^{\text {th }}$ edition. Gregg Division, McGrawHill. 1983; 374.

13. John S, Timothy EL. "Modern polyesters: chemistry and technology of polyesters and co-polyesters". John Wiley and Sons. 2003.

14. Tony YLR, Xu C. polyester fiber Manual ( $2^{\text {nd }}$ edition). Textile Industry Press. 1995.

15. Kopnick H, Schmidt M, Brugging W, Ruter J, Kaminsky W. Polyesters, In: Ullmann's Encyclopedia of Industrial Chemistry. Wiley-VCH, A21. 2003; 227250. 